\title{
The value of CT imaging for COVID-19 pneumonia: report of a false-negative nucleic acid test case
}

\author{
Chun-Yan Lu ${ }^{1}$, Hong-Li Bai ${ }^{1}$, Yuan Yuan ${ }^{1}$, Qiang Lu ${ }^{2}$ \\ ${ }^{1}$ Department of Radiology, ${ }^{2}$ Department of Ultrasound, West China Hospital of Sichuan University, Chengdu 610041, China \\ Correspondence to: Qiang Lu, MD. Department of Ultrasound, West China Hospital of Sichuan University, Chengdu 610041, China. \\ Email: wsluqiang@126.com.
}

Submitted Feb 07, 2020. Accepted for publication Mar 11, 2020.

doi: $10.21037 /$ jtd.2020.03.62

View this article at: http://dx.doi.org/10.21037/jtd.2020.03.62

In this brief letter we would like to refer to you some information about the value of CT imaging for corona virus disease 2019 (COVID-19) pneumonia in cases which have inconsistent COVID-19 nucleic acid test.

A 34-year-old man had a 1-day history of fever $\left(39.0^{\circ} \mathrm{C}\right)$ entered our hospital who resided in Wuhan, China (COVID-19 epicenter) but had traveled to Chengdu, China. The detection of Influenza A, B virus antigens was negative. Real-time fluorescence polymerase chain reaction of the patient's nasopharyngeal specimen was positive for the COVID-19 nucleic acid test (NAT) (Jan. 22, 2020). Chest computed tomography (CT) (Figure 1, Jan. 22, 2020) displayed slightly high density and obscure patchy shadows in the apical segment of the right upper lobe, suggesting inflammation. He was diagnosed COVID-19 in our hospital and then transferred to Chengdu Public Health Clinical Medical Center (the government-designated hospital for COVID-19 pneumonia). However, in the latter hospital, COVID-19 pneumonia was excluded because two consecutive COVID-19 NATs were negative. The patient was subsequently discharged. Nevertheless, he still had intermittent fever and came to our hospital again on Jan. 28, 2020. CT showed progressive ground-glass opacities of the upper lobe of the right lung (Figure 2A,B, Jan. 28, 2020). The diagnosis of COVID-19 pneumonia was confirmed again by a positive COVID-19 NAT on the same day. A subsequent chest CT images showed further progressive ground-glass opacities of the right lung upper lobe (Figure $3 A, B$, Feb. 1, 2020). After antiviral treatment, the patient was discharged with three consecutive negative COVID-19 NATs and improved CT images (Figure 4, Feb. 8, 2020) on Feb. 10, 2020.

In December 2019, an outbreak of COVID-19 pneumonia began in Wuhan (Hubei, China). According to current diagnostic criteria, laboratory examination such as swab test has become a standard and formative assessment for the diagnosis of COVID-19 (1-4). However, many clinical experts reported orally that the positive rate of NAT was low, even only 30-50\%. Some patients experienced multiple negative NATs before definitive diagnosis. Fang et al. also reported in a series of 51 patients with chest CT and RT-PCR assay performed within 3 days, the sensitivity of CT for COVID-19 infection was $98 \%$ compared to RTPCR sensitivity of $71 \%$ (5). False negative results may occur due to the influence of COVID-19 nucleic acid detection extraction method, kit sensitivity, variation in detection rate from different manufacturers, insufficient viral material in the specimen, low patient viral load, and other factors $(5,6)$. The case we reported experienced NAT four times and the results were contradictory, which we speculated was due to the use of kits from different manufacturers (Sansure Biotech for our hospital, while Daan gene co. LTD for another). When COVID-19 pneumonia was highly suspected clinically, inconsistent COVID-19 NAT results may lead to confusion in diagnosis.

To address this problem, HRCT can clearly show pulmonary lesions and their progress, providing valuable evidence for clinical diagnosis (4,7-9). Typical CT findings for COVID-19 pneumonia included bilateral pulmonary parenchymal ground-glass and consolidative pulmonary opacities, sometimes with a rounded morphology and a peripheral lung distribution (7). In clinically suspicious cases with typical positive CT image findings, patient isolation and repeat COVID-19 NAT is required to avoid misdiagnosis and prevent the spreading of this disease. 


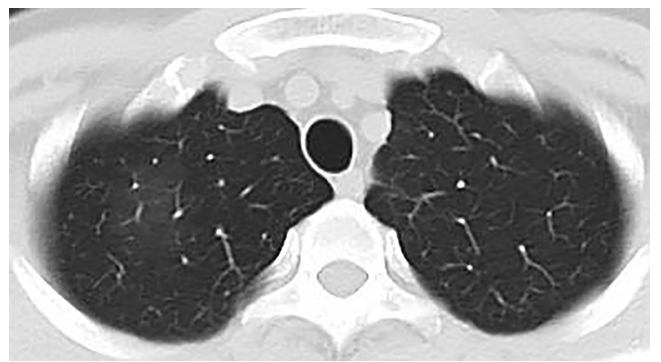

Figure 1 Transverse chest CT image from a 34-year-old man showing slightly high density and obscure patchy shadows in the apical segment of the right lung upper lobe on Day 2 after symptom onset.
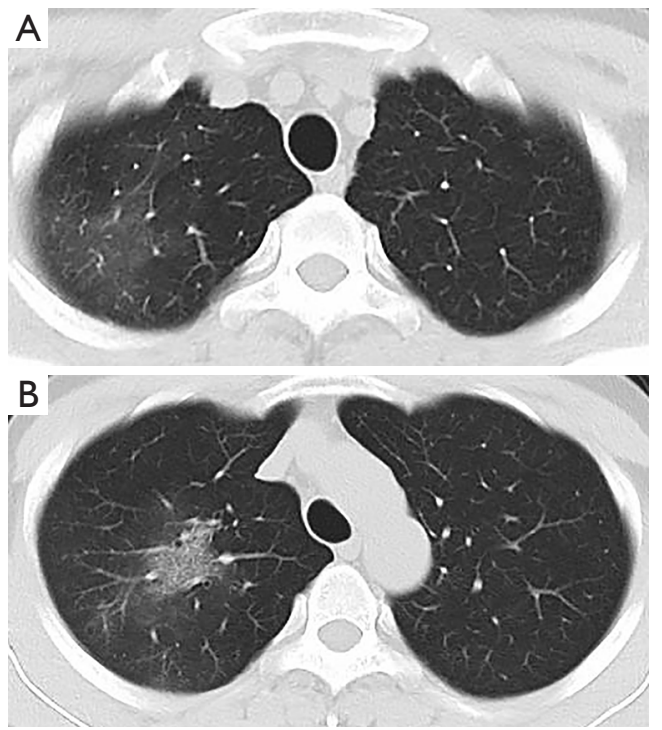

Figure 2 CT images showing progressive ground-glass opacities of the right lung upper lobe on Day 7 after symptom onset. Compared with previous CT image (Figure 1), the lesions were enlarged and the density of lung opacities were higher.

Meanwhile, mimics of COVID-19, such as other known viral pneumonia (including influenza virus, adenovirus, respiratory syncytial virus, etc.), mycoplasmal pneumonia, and non-infectious pneumonia (including vasculitis, acute interstitial pneumonia, organizing pneumonia, etc.) should be considered to avoid misdiagnosis and excessive anxiety.

In conclusion, for positive COVID-19 NAT cases, CT can show pulmonary lesions and monitor the changes of lung lesions on some rapidly progressive patients, provide a baseline
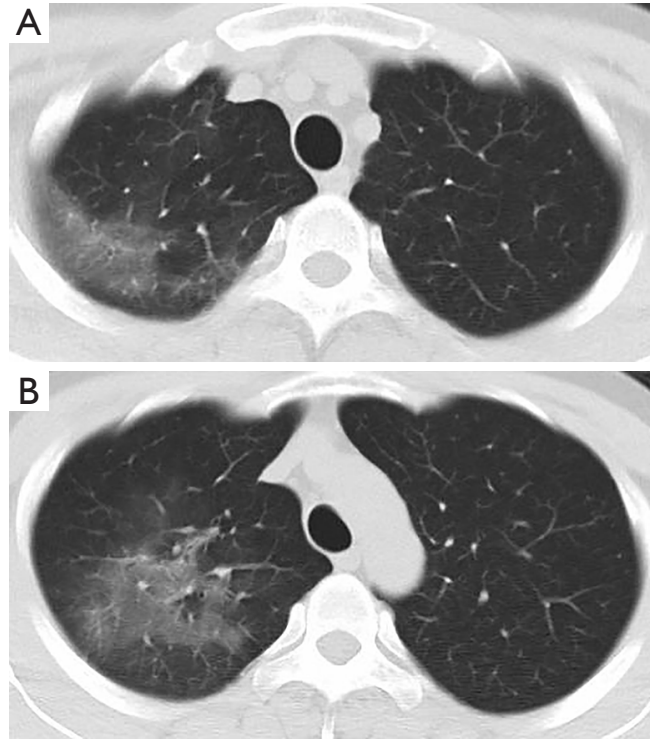

Figure 3 CT images showing further progressive ground-glass opacities of the right lung upper lobe on Day 11 after symptom onset.

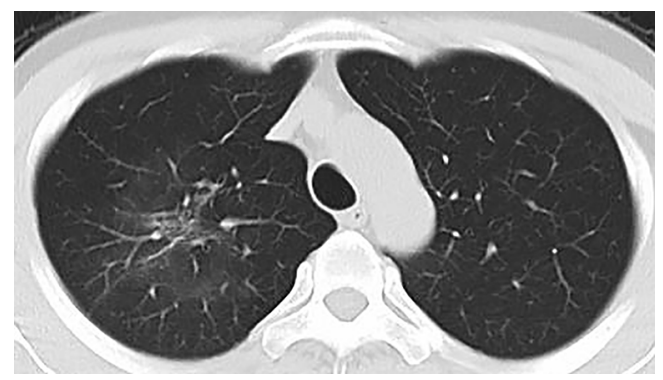

Figure 4 CT image showing improved ground-glass opacities of the right lung upper lobe on Day 18 after symptom onset. Compared with previous CT images (Figure 3), the lesions were decreased and the density of lung opacities were lower.

for the evaluation of treatment, while for negative COVID-19 NAT cases, we recommend CT screening and assisting clinical diagnosis COVID-19 for patients with clinical and epidemiologic features compatible with COVID-19 infection.

\section{Acknowledgements}

We thank Prof. Dong-Tao Lin for copyediting this letter. Funding: None. 


\section{Footnote}

Conflicts of Interest: All authors have completed the ICMJE uniform disclosure form (available at http://dx.doi. org/10.21037/jtd.2020.03.62). The authors have no conflicts of interest to declare.

Ethical Statement: The authors are accountable for all aspects of the work in ensuring that questions related to the accuracy or integrity of any part of the work are appropriately investigated and resolved.

Open Access Statement: This is an Open Access article distributed in accordance with the Creative Commons Attribution-NonCommercial-NoDerivs 4.0 International License (CC BY-NC-ND 4.0), which permits the noncommercial replication and distribution of the article with the strict proviso that no changes or edits are made and the original work is properly cited (including links to both the formal publication through the relevant DOI and the license). See: https://creativecommons.org/licenses/by-nc-nd/4.0/.

\section{References}

1. Li Q, Guan X, Wu P, et al. Early Transmission Dynamics in Wuhan, China, of Novel Coronavirus-Infected Pneumonia. N Engl J Med 2020. [Epub ahead of print].

2. Wang C, Horby PW, Hayden FG, et al. A novel

Cite this article as: Lu CY, Bai HL, Yuan Y, Lu Q. The value of CT imaging for COVID-19 pneumonia: report of a falsenegative nucleic acid test case. J Thorac Dis 2020;12(5):28272829. doi: $10.21037 /$ jtd.2020.03.62 coronavirus outbreak of global health concern. Lancet 2020;395:470-3.

3. Zhu N, Zhang D, Wang W, et al. A Novel Coronavirus from Patients with Pneumonia in China, 2019. N Engl J Med 2020. [Epub ahead of print].

4. China National Health Commission. Diagnosis and treatment of pneumonitis caused by new coronavirus (trial version 6). Beijing: China National Health Commission, 2020. http://www.nhc.gov.cn/xcs/zhengcwj/202002/8334a 8326dd94d329df351d7da8aefc2/files/b218cfeb1bc54639af 227f922bf6b817.pdf (accessed Feb 19, 2020).

5. Fang Y, Zhang H, Xie J, et al. Sensitivity of Chest CT for COVID-19: Comparison to RT-PCR. Radiology 2020. [Epub ahead of print].https://doi.org/10.1148/ radiol.2020200432. Published online Feb 192020.

6. Xie X, Zhong Z, Zhao W, et al. Chest CT for typical 2019-nCoV pneumonia: relationship to negative RT-PCR testing. Radiology 2020. [Epub ahead of print].

7. Chung M, Bernheim A, Mei X, et al. CT Imaging Features of 2019 Novel Coronavirus (2019-nCoV). Radiology 2020;295:202-7.

8. Kay F, Abbara S. The Many Faces of COVID-19: Spectrum of Imaging Manifestations. Radiol Cardiothorac Imaging 2020. doi. 10.1148/ryct.2020200037.

9. Pan F, Ye T, Sun P, et al. Time Course of Lung Changes On Chest CT During Recovery From 2019 Novel Coronavirus (COVID-19) Pneumonia. Radiology 2020. doi. 10.1148/radiol.2020200370. 